\title{
Idiosyncratically tuned switching behavior of riboswitch aptamer domains revealed by comparative small-angle X-ray scattering analysis
}

\author{
NATHAN J. BAIRD ${ }^{1}$ and ADRIAN R. FERRÉ-D'AMARÉ ${ }^{1,2}$ \\ ${ }^{1}$ Howard Hughes Medical Institute, Fred Hutchinson Cancer Research Center, Seattle, Washington 98109-1024, USA \\ ${ }^{2}$ Division of Basic Sciences, Fred Hutchinson Cancer Research Center, Seattle, Washington 98109-1024, USA
}

\begin{abstract}
Riboswitches are structured mRNA elements that regulate gene expression upon binding specific cellular metabolites. It is thought that the highly conserved metabolite-binding domains of riboswitches undergo conformational change upon binding their cognate ligands. To investigate the generality of such a mechanism, we employed small-angle X-ray scattering (SAXS). We probed the nature of the global metabolite-induced response of the metabolite-binding domains of four different riboswitches that bind, respectively, thiamine pyrophosphate (TPP), flavin mononucleotide (FMN), lysine, and S-adenosyl methionine (SAM). We find that each RNA is unique in its global structural response to metabolite. Whereas some RNAs exhibit distinct free and bound conformations, others are globally insensitive to the presence of metabolite. Thus, a global conformational change of the metabolite-binding domain is not a requirement for riboswitch function. It is possible that the range of behaviors observed by SAXS, rather than being a biophysical idiosyncrasy, reflects adaptation of riboswitches to the regulatory requirements of their individual genomic context.
\end{abstract}

Keywords: RNA folding; aptamers; metabolites; riboswitch; small-angle X-ray scattering

\section{INTRODUCTION}

Riboswitches are gene-regulatory mRNA domains that respond to the intracellular concentration of their cognate small molecules by modulating transcription or translation in bacteria and pre-mRNA splicing or polyadenylation in eukaryotes. More than a dozen classes of riboswitches specific for a variety of metabolites have been discovered and characterized biochemically (Winkler and Breaker 2005; Edwards et al. 2007; Henkin 2008). For all riboswitch classes examined, phylogenetic sequence analyses delineate a segment of highly conserved sequence that is necessary and sufficient for specific in vitro binding to their cognate metabolites. By analogy to RNAs evolved in vitro to bind particular ligands (Ellington and Szostak 1990), these riboswitch segments have been termed the "aptamer domain" (Winkler et al. 2002). Aptamer domain conservation can

Reprint requests to: Adrian R. Ferré-D’Amaré, Howard Hughes Medical Institute and Division of Basic Sciences, Fred Hutchinson Cancer Research Center, 1100 Fairview Avenue North, Seattle, WA 98109-1024, USA; e-mail: aferre@fhcrc.org; fax: (206) 667-3331.

Article published online ahead of print. Article and publication date are at http://www.rnajournal.org/cgi/doi/10.1261/rna.1852310. extend to fine structural details. Crystallographic structure determination of Escherichia coli and Arabidopsis thaliana thi-box aptamer domains revealed that these RNAs from distantly related organisms adopt virtually identical threedimensional (3D) structures and recognize thiamine pyrophosphate (TPP) through identical interactions (Edwards and Ferré-D’Amaré 2006; Serganov et al. 2006; Thore et al. 2008). The moieties of riboswitches that interface with the transcriptional, translational, or RNA processing machinery, ultimately giving rise to alteration of gene expression, vary greatly even between instances of the same class of riboswitch in different genomic loci of one organism. These variable segments of riboswitches that modulate gene expression have been termed the "expression platform" (Winkler et al. 2002).

The molecular nature of the functional coupling between riboswitch aptamer and expression platform domains remains poorly understood (Wickiser et al. 2005a,b). The structural dynamics of the aptamer and expression platform domains may play an important role. However, regardless of the particulars of these interactions, the modular, self-contained function of the aptamer domain, implied by sequence conservation and borne out by biochemical 
analyses, indicates that changes in molecular properties of this domain that arise from cognate small molecule binding are central to riboswitch function. Early in-line probing studies indicated that the aptamer domains of some riboswitches adopt distinct free and metabolite-bound conformations and, in fact, suggested that the aptamer and expression platform domains were structurally and functionally separable (Winkler et al. 2002). These studies, other chemical probing experiments, and NMR and fluorescence spectrometric studies (see below) have provided a nucleotideby-nucleotide description of the changes in molecular properties of several riboswitch aptamer domains between their free and bound states.

Do all riboswitch aptamer domains undergo global, large-scale conformational changes concomitant with the local ligand binding-induced rearrangements detected by chemical probing and spectrometry? A detailed small-angle X-ray scattering (SAXS) analysis of the glycine riboswitch aptamer domain from Vibrio cholerae revealed dramatic conformational changes of the RNA as a function of ligand occupancy (Lipfert et al. 2007). Analytical ultracentrifugation studies of the aptamer domain of the $m g t E$ magnesium riboswitch from Bacillus subtilis revealed a highly cooperative $\mathrm{Mg}^{2+}$-dependent compaction (Dann et al. 2007). Studies of purine riboswitch aptamer domains employing 2-aminopurine fluorescence, SHAPE, NMR, nuclease mapping, mutational analysis, and single-molecule FRET and force-extension experiments (Lemay et al. 2006; Noeske et al. 2006, 2007; Gilbert et al. 2007; Ottink et al. 2007; Rieder et al. 2007; Stoddard et al. 2008) arrived at conflicting conclusions. Metabolite-induced large-scale structural changes were suggested by some studies, while other studies implied that conformational changes were limited to the metabolite-binding pocket. Further adding to the apparent inconsistency in the switching behavior of aptamer domains are crystallographic studies of the lysine riboswitch aptamer domain: The free and ligand-bound structures were found to be essentially indistinguishable (Garst et al. 2008; Serganov et al. 2008). SAXS analyses of this aptamer domain under highly stabilizing ionic conditions $\left(5-10 \mathrm{mM} \mathrm{Mg}^{2+}\right.$ ) reached the same conclusion (Garst et al. 2008). Overall, these results could imply that there are two types of riboswitch aptamer domains-those that undergo global conformational changes concomitant with ligand binding and those that do not (Montange and Batey 2008). Alternatively, the apparent disparity may simply be a reflection of the diversity of techniques employed: The presence or absence of global conformational changes has sometimes been inferred from the response of local molecular probes to metabolite binding.

In this study, we examine the global conformational changes of aptamer domains from riboswitches that respond to four different metabolites under the same solution conditions and employing the same technique: SAXS. We selected for SAXS analysis the aptamer domains of the
TPP-responsive thi-box riboswitch, the class I $S$-adenosyl methionine (SAM)-responsive riboswitch (SAM-I), the flavin mononucleotide (FMN)-responsive riboswitch, and the lysine-responsive L-box riboswitch. X-ray crystallographic structures of the metabolite-bound forms of all four have been reported, allowing us to benchmark the solution SAXS studies of the metabolite-bound states. Our comparative SAXS analyses reveal a distinct global structural response to ligand binding for each of the RNAs examined.

\section{RESULTS}

\section{Distinct free and bound conformations of the thi-box riboswitch aptamer domain}

We first examined the solution behavior of an 83-nucleotide (nt) RNA construct that encompasses the aptamer domain of the E. coli thiM TPP-responsive riboswitch (Fig. 1A). Guinier analysis indicates that under approximately physiologic $\mathrm{Mg}^{2+}$ concentration $(\sim 1.5 \mathrm{mM})$ (Batey et al. 2004) and in the absence of TPP, this RNA exhibits a radius of gyration $\left(R_{\mathrm{g}}\right)$ of $27.5 \AA$ (Table 1$)$. This is considerably larger than the $\sim 24.6-\AA R_{\mathrm{g}}$ calculated (Materials and Methods) from crystal structures of the TPP-bound thiM riboswitch (Edwards and Ferré-D'Amaré 2006; Serganov et al. 2006). Addition of saturating TPP $(100 \mu \mathrm{M})$ resulted in a decrease of $R_{\mathrm{g}}$ to $24.1 \AA$ (Table 1 ), which is slightly more compact than predicted from the crystal structure (see Materials and Methods). Since the precise concentration (strictly, activity) of free $\mathrm{Mg}^{2+}$ encountered by the riboswitch in vivo might be somewhat higher, we also examined it in the presence of $2.5 \mathrm{mM} \mathrm{Mg}^{2+}$. In the absence of TPP, we observe a $\mathrm{Mg}^{2+}$-induced compaction of $R_{\mathrm{g}}$ from $27.5 \AA$ ( $1.5 \mathrm{mM}$ $\left.\mathrm{Mg}^{2+}\right)$ to $25.7 \AA\left(2.5 \mathrm{mM} \mathrm{Mg}{ }^{2+}\right)$. Addition of saturating TPP $(100 \mu \mathrm{M})$ at this slightly higher $\mathrm{Mg}^{2+}$ concentration did result in further compaction of $R_{\mathrm{g}}$ to $21.9 \AA$. Comparison of the electron pair-probability, or $P(r)$, distributions for the metabolite-free and metabolite-bound (hereafter "free" and "bound") states indicates that this reduction in $R_{\mathrm{g}}$ is accompanied by a conformational change of the RNA (Fig. 2B).

The observed $\mathrm{Mg}^{2+}$-induced compaction of the thi-box aptamer domain in the free state between $1.5 \mathrm{mM}$ and 2.5 $\mathrm{mM} \mathrm{Mg}{ }^{2+}$ in the absence of TPP suggests that a highly stabilizing $\mathrm{Mg}^{2+}$ concentration may induce additional global collapse without the need for TPP and perhaps result in a conformation that is similar to that of the bound state crystal structures. To test this idea, we increased the $\mathrm{Mg}^{2+}$ concentration to $10 \mathrm{mM} \mathrm{Mg}{ }^{2+}$ in the absence of TPP and measured an $R_{\mathrm{g}}$ of $24.4 \AA$, a slight compaction relative to that observed for the free state under physiologic $\mathrm{Mg}^{2+}$ concentration. Comparison of the $P(r)$ distributions confirms that even under these highly stabilizing $\mathrm{Mg}^{2+}$ conditions, the global shape of the free RNA is similar to that of the free state under physiologic $\mathrm{Mg}^{2+}$ (Fig. 2B). Hence, 

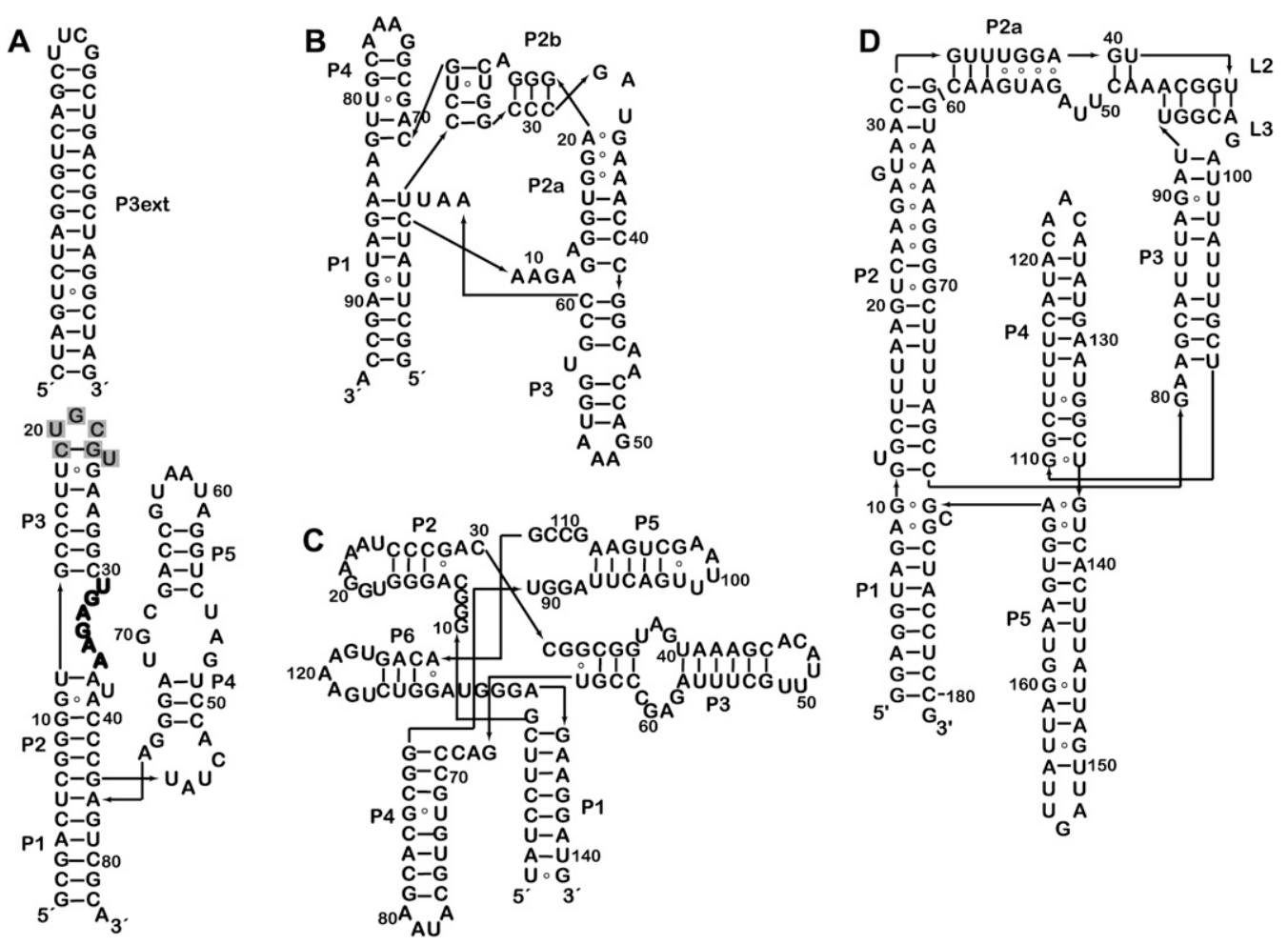

FIGURE 1. Sequence and schematic secondary structures of the riboswitch aptamer domains employed in this study. Secondary structure diagrams are organized similar to available 3D structures for riboswitch aptamers that bind $(A)$ TPP, $(B)$ SAM, $(C)$ FMN, and $(D)$ lysine. (P3ext) The helical extension added to P3 of the TPP aptamer domain $(A)$. (Gray) The nucleotides removed from the wild-type sequence upon introduction of the extension. The T-loop between P2 and P3, which is responsible for recognition of the pyrimidine moiety of TPP, is highlighted in bold letters.

$10 \mathrm{mM} \mathrm{Mg}^{2+}$ is insufficient to stabilize the globally compact conformation. The addition of saturating TPP under this highly stabilizing $\mathrm{Mg}^{2+}$ condition did result in a global size and shape indistinguishable from that of the bound state at $2.5 \mathrm{mM} \mathrm{Mg}^{2+}$ (Fig. 2B).

To confirm that the TPP-bound conformation of the thiM thi-box riboswitch in solution corresponds to that observed in crystal structures, we computed low-resolution $3 \mathrm{D}$ reconstructions from the SAXS data employing the program DAMMIN (Svergun 1999). Multiple independent reconstructions using initial search volumes in the range of 76-106 ̊ robustly converged into essentially identical reconstructions that can be superimposed on crystal structures of the TPP-bound aptamer domain of the thi-box riboswitch (Fig. 3A). Overall, reconstructions of bound states calculated from SAXS data collected at various $\mathrm{Mg}^{2+}$ concentrations exhibited similar shapes. The main difference, for example, between the bound-state reconstructions at $1.5 \mathrm{mM}$ and $10 \mathrm{mM} \mathrm{Mg}^{2+}$ is a reduction of the longest (maximum) dimension $\left(D_{\max }\right)$ from 80 to $74 \AA$ for the latter condition (Table 1).

To gain insight into thi-box structural changes induced by TPP binding, we generated 3D reconstructions from our SAXS data of the aptamer domain in the absence of TPP at $1.5 \mathrm{mM}$ and $2.5 \mathrm{mM} \mathrm{Mg}^{2+}$ concentrations. These recon- structions robustly converged to low-resolution molecular envelopes whose dimensions and shapes are more elongated than those of the bound-state reconstructions (Fig. 3B,C). Similarly to what we observed for reconstructions of the bound state, reconstructions generated from free-state SAXS data measured at various $\mathrm{Mg}^{2+}$ concentrations resulted in electron density distributions that differed between each other in longest linear dimension but not substantively in overall shape. Because crystal or NMR structures of the ligand-free form of the thi-box riboswitch have not been reported, we could not immediately interpret the lowresolution envelope in terms of a detailed molecular model.

In order to interpret the low-resolution reconstruction, we engineered the RNA to contain an additional structural

TABLE 1. Global SAXS parameters for the TPP aptamer domain

\begin{tabular}{lccccc}
\hline$\left[\mathrm{Mg}^{2+}\right]$ & \multicolumn{2}{c}{$R_{\mathrm{g}}( \pm 1 \AA)$} & & \multicolumn{2}{c}{$D_{\max }( \pm 5 \AA)$} \\
\cline { 2 - 3 } \cline { 6 - 7 }$(\mathrm{mM})$ & Free & Bound & & Free & Bound \\
\hline 1.5 & 27.5 & 24.1 & & 90 & 80 \\
2.5 & 25.7 & 21.9 & & 83 & 78 \\
10 & 24.4 & 22.1 & & 80 & 74 \\
\hline
\end{tabular}

The $R_{\mathrm{g}}$ calculated from a crystal structure (PDB ID $2 \mathrm{HOJ}$ ) is $24.6 \AA$. 

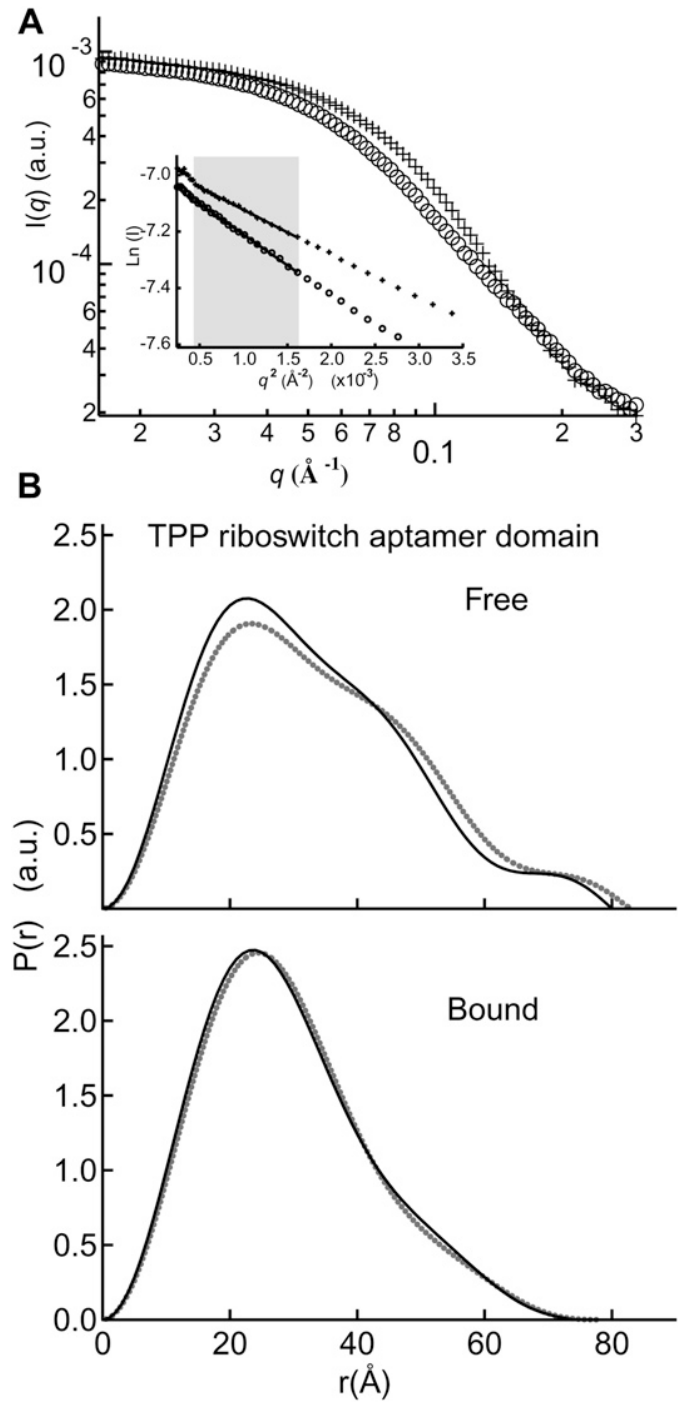

FIGURE 2. Metabolite-induced conformational switch in the TPP aptamer domain. (A) Sample raw scattering data and (insert) Guinier plots for determination of $R_{\mathrm{g}}$; (circles) TPP-free; (crosses) TPPbound. Most Guinier analyses in the present study were performed within the $q$ range indicated by the shaded gray box. (B) $P(r)$ plot detailing the differences in shape and maximum dimension between the free and bound conformations at $2.5 \mathrm{mM} \mathrm{Mg}^{2+}$ (gray dots) and $10 \mathrm{mM} \mathrm{Mg}^{2+}$ (black lines). (a.u.) Arbitrary units.

unit, not present in the wild type. This approach has been previously employed, for instance, by Nakamura et al. (1995) to facilitate interpretation of electron micrographs of the group I intron. In the TPP-bound state, the thi-box aptamer domain adopts an inverted h-shaped structure, with the metabolite spanning two of the arms of the RNA (Fig. 1A). The pyrophosphate moiety of TPP is recognized by a helix that is capped by loop L5 (the "pyrophosphate sensor helix") and the aminopyrimidine ring at the opposite end of the metabolite is bound by a T-loop motif within a helical stack (the "pyrimidine sensor helix") that is capped by loop L3 (Thore et al. 2006). Other studies have demonstrated that L3 is functionally and structurally dispensable (Kulshina et al. 2010). Therefore, we generated a variant thi-box riboswitch with a 15 base-pair extension in the distal portion of the pyrimidine sensor helix (P3ext) (Fig. 1A). SAXS experiments demonstrate that like the wild-type aptamer domain, this extended construct undergoes a large-scale change in size and shape upon TPP binding (data not shown). Three-dimensional reconstructions of this engineered aptamer domain generated from SAXS data collected in the absence of TPP reveal a molecular envelope that is in general agreement with that of the free state of the wild-type thiM riboswitch, except for the presence of a significantly more elongated density that most likely corresponds to the extended P3 helix (Fig. 3D, black). This interpretation assumes that under the solution conditions employed, the metabolite-free aptamer domain assumes a distinct, highly populated conformation. With this caveat, our SAXS reconstructions suggest that the aptamer domain undergoes a global rearrangement upon loss of the bound ligand that results from unfolding of the internal T-loop in P3, which is responsible for recognition of the aminopyrimidine moiety of TPP (Fig. 1A, bold). Although a detailed description of the TPP-free conformation(s) of the thi-box will require further studies, our SAXS analysis indicates that under physiological $\mathrm{Mg}^{2+}$ concentrations in solution, this riboswitch adopts a ligand-free conformation that is distinctly different in global size and shape from the TPP-bound conformation.

\section{Metabolite and $\mathrm{Mg}^{2+}$-dependent switching of the SAM-I aptamer domain}

We next examined the solution behavior of a 94-nt aptamer domain construct of the class I SAM-responsive riboswitch (SAM-I) of the metF-metH2 operon of Thermoanaerobacter tengcongensis (Fig. 1B). Guinier analysis of SAXS data collected from this construct at $1.5 \mathrm{mM} \mathrm{Mg}^{2+}$ concentration shows that the $R_{\mathrm{g}}$ of the SAM-I aptamer domain compacts from $29.9 \AA$ in the absence of SAM to $26.3 \AA$ in the presence of saturating (1 mM) SAM (Table 2). A 2.9$\AA$-resolution crystal structure of the metabolite-bound form of this RNA domain has previously been reported (Montange and Batey 2006). The $R_{\mathrm{g}}$ calculated from the crystal structure is $\sim 26 \AA$, in good agreement with the $R_{g}$ of the bound state determined in solution by SAXS in the presence of $1.5 \mathrm{mM} \mathrm{Mg}^{2+}$.

Because the TPP riboswitch aptamer domain exhibited considerable $\mathrm{Mg}^{2}$-induced compaction, we investigated the free and bound states of the SAM-I aptamer domain under $\mathrm{Mg}^{2+}$ concentrations of $2.5 \mathrm{mM}$ and $10 \mathrm{mM}$. The free and bound state $R_{\mathrm{g}}$ 's observed at $2.5 \mathrm{mM} \mathrm{Mg}^{2+}$ concentration are identical, within experimental error, to those observed at $1.5 \mathrm{mM} \mathrm{Mg}^{2+}$. Remarkably, however, addition of $10 \mathrm{mM}$ $\mathrm{Mg}^{2+}$ results in compaction of the free state to an $R_{\mathrm{g}}$ of $27.5 \AA$ (compared to $29.2 \AA$ at $2.5 \mathrm{mM} \mathrm{Mg}^{2+}$ ) (Table 2). 
A

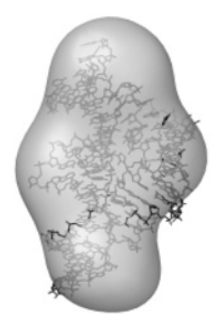

B

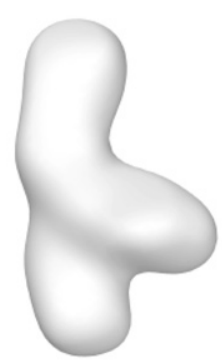

C

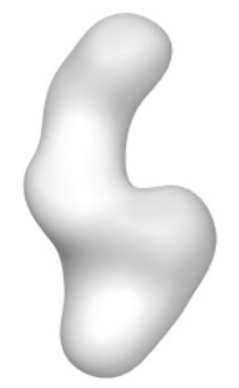

FIGURE 3. Low-resolution SAXS models of the TPP aptamer domain. (A) DAMMIN reconstruction of the bound conformation. The crystal structure is docked within it to demonstrate the agreement in size and shape. The correlation coefficient between the reconstruction and the envelope calculated from the crystal structure (Edwards and FerréD'Amaré 2006) is 0.89 (Wriggers et al. 1999). (B) Low-resolution model of the "free" form in the presence of $2.5 \mathrm{mM} \mathrm{Mg}^{2+}$. (C) Reconstruction of the free conformation in $1.5 \mathrm{mM} \mathrm{Mg}^{2+}$ is in general agreement with that at $2.5 \mathrm{mM} \mathrm{Mg}^{2+}$, although slightly expanded. (D) Lowresolution model of the P3ext variant $\left(1.5 \mathrm{mM} \mathrm{Mg}^{2+}\right)$ demonstrates an additional density (black) in the $\mathrm{P} 3$ region.

Thus, high $\mathrm{Mg}^{2+}$ concentrations alone are capable of stabilizing a global conformation similar to the bound conformation of the SAM-I aptamer domain at $2.5 \mathrm{mM} \mathrm{Mg}^{2+}$. It is important to note, however, that the $P(r)$ distribution of the free state observed in $10 \mathrm{mM} \mathrm{Mg}{ }^{2+}$ is intermediate between those observed for the free and bound states at physiologic $\mathrm{Mg}^{2+}$ (Fig. 4). Addition of saturating SAM in the presence of $10 \mathrm{mM} \mathrm{Mg}{ }^{2+}$ results in a bound conformation that exhibits global size and shape parameters identical to those determined for the bound state in $2.5 \mathrm{mM}$ $\mathrm{Mg}^{2+}$ (Fig. 4).

\section{No global switching of FMN riboswitch aptamer domain}

Next, we examined the 141-nt aptamer domain of the ribD FMN-binding riboswitch of B. subtilis (Fig. 1C). When examined in the absence of FMN at $1.5 \mathrm{mM} \mathrm{Mg}^{2+}$, this RNA exhibits an $R_{\mathrm{g}}$ of $29.4 \AA$ (Table 3). Remarkably, the $R_{\mathrm{g}}$ and $D_{\max }$ remain unchanged, within experimental error, in the presence of saturating FMN $(100 \mu \mathrm{M})$. Unlike our experiments with the SAM-I aptamer domain (above), addition of $10 \mathrm{mM} \mathrm{Mg}^{2+}$ did not result in further reduction of $R_{\mathrm{g}}$ of this aptamer domain. Moreover, analysis of the $P(r)$ distribution indicates that only subtle conformational differences, if any, exist between the free and bound states of this RNA, even in the presence of $10 \mathrm{mM} \mathrm{Mg}^{2+}$ (Fig. 5). A $2.95-\AA$-resolution crystal structure of the aptamer domain of the impX FMN riboswitch from Fusobacterium nucleatum has been reported (Serganov et al. 2009). The $R_{\mathrm{g}}$ calculated from the crystal structure is $28 \AA$, which is in good agreement with that of the B. subtilis ribD FMN aptamer domain we examined by SAXS. We conclude that

D

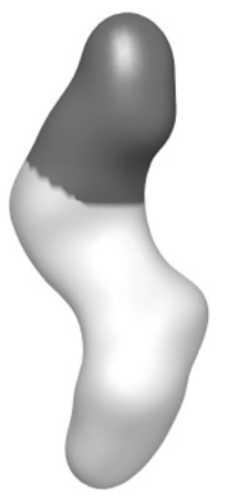

the FMN riboswitch aptamer domain from B. subtilis adopts the same global conformation irrespective of the presence of its cognate ligand in either physiologic or high $\mathrm{Mg}^{2+}$ concentrations.

\section{Ligand-independent switching of the lysine riboswitch aptamer domain}

Previously, it was reported that the aptamer domain of the lys $C$ lysine riboswitch from $B$. subtilis exhibited indistinguishable $R_{\mathrm{g}}$ and $P(r)$ in the presence and absence of saturating lysine concentrations when examined in $5 \mathrm{mM} \mathrm{Mg}^{2+}$ (Garst et al. 2008). To evaluate the generality of these observations, we carried out SAXS experiments with a 181-nt construct from a different organism. Our construct encompasses the lisA lysine riboswitch aptamer domain from Clostridium acetobutylicum (Fig. 1D). Guinier and $P(r)$ distribution analyses of SAXS data from this aptamer domain demonstrate that in $1 \mathrm{mM} \mathrm{Mg}^{2+}$, the $R_{\mathrm{g}}$ is $\sim 43 \AA$ and the $D_{\max }$ is $\sim 145 \AA$, both in the absence and presence of $1 \mathrm{mM}$ lysine (Table 4). The $P(r)$ distributions are also nearly identical under the two conditions (Fig. 6). Interestingly, the radii of gyration observed in the absence and presence of lysine at $1 \mathrm{mM} \mathrm{Mg}{ }^{2+}$ concentration are considerably larger than expected given the two reported crystal structures (see below and Table 4).

We next examined the C. acetobutylicum lysine riboswitch aptamer domain by SAXS at $10 \mathrm{mM} \mathrm{Mg}^{2+}$. We find that, under these conditions, this aptamer exhibits $R_{\mathrm{g}}$ of $\sim 39 \AA$ and $D_{\max }$ of $\sim 125 \AA$, both in the absence and presence of lysine (Table 4). Several additional $\mathrm{Mg}^{2+}$ and lysine concentrations, such as $0.5,2.5$, and $5 \mathrm{mM} \mathrm{Mg}^{2+}$ and serial 10 -fold dilutions of lysine from $10^{-2}$ to $10^{-8} \mathrm{M}$, were tested to investigate if conditions exist under which lysine would induce a global conformational switch of the aptamer. Under all conditions examined, the lysine riboswitch aptamer domain from C. acetobutylicum is highly sensitive to $\mathrm{Mg}^{2+}$ concentration but globally insensitive to

TABLE 2. Global SAXS parameters for the SAM-I aptamer domain

\begin{tabular}{lccccc}
\hline$\left[\mathrm{Mg}^{2+}\right]$ & \multicolumn{2}{c}{$R_{\mathrm{g}}( \pm 1 \AA)$} & & \multicolumn{2}{c}{$D_{\max }( \pm 5 \AA)$} \\
\cline { 2 - 3 }$(\mathrm{mM})$ & Free & Bound & & Free & Bound \\
\hline 1.5 & 29.9 & 26.3 & & 95 & 89 \\
2.5 & 29.2 & 26.2 & & 92 & 85 \\
10 & 27.5 & 26.4 & & 87 & 85 \\
\hline
\end{tabular}

The $R_{\mathrm{g}}$ calculated from a crystal structure (PDB ID 2GIS) is $25.8 \AA$. 


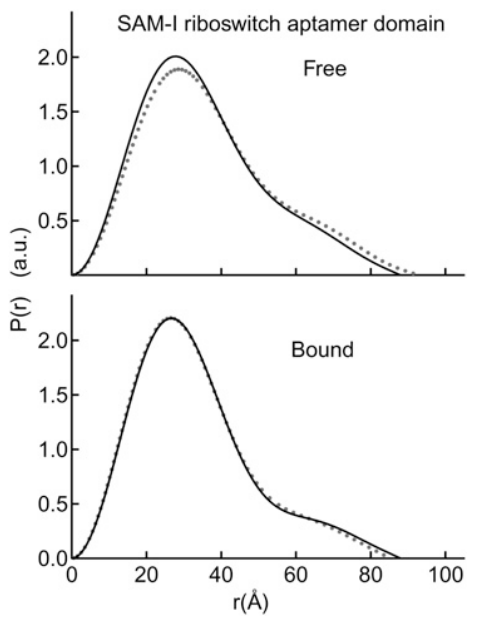

FIGURE 4. Conformational switching induced by $\mathrm{Mg}^{2+}$ and metabolite in the SAM-I aptamer domain. Two $P(r)$ plots reveal changes in $D_{\max }$ and global conformations between the free and bound states in the presence of $2.5 \mathrm{mM} \mathrm{Mg}^{2+}$ (gray dots) and $10 \mathrm{mM} \mathrm{Mg}^{2+}$ (black lines). The bound conformation is identical for the $2.5 \mathrm{mM}$ and $10 \mathrm{mM} \mathrm{Mg}{ }^{2+}$, rendering the $2.5 \mathrm{mM}$ trace (gray dots) largely obstructed from view.

the presence of lysine (Fig. 6; Table 4). In fact, the $\mathrm{Mg}^{2+}$ concentration can be reduced to $5 \mathrm{mM}$, and the aptamer domain still maintains global size and shape indistinguishable from those observed in the presence of $10 \mathrm{mM} \mathrm{Mg}^{2+}$.

Previously, two crystal structures of the asd lysine riboswitch aptamer domain from the thermophilic bacterium Thermotoga maritima have been reported at $1.9 \AA$ (Serganov et al. 2008) and 2.8- $\AA$ resolution (Garst et al. 2008). The $R_{\mathrm{g}}$ calculated from the crystal structure of the 161-nt aptamer domain is $33.9 \AA$ (Materials and Methods). Since the T. maritima aptamer domain sequence is shorter than those of either the B. subtilis or C. acetobutylicum aptamer domains, the $R_{\mathrm{g}}$ 's observed by SAXS for both constructs at $5 \mathrm{mM} \mathrm{Mg}^{2+}$ (Table 4; Garst et al. 2008) are consistent with the overall structure of the mesophilic RNAs in solution being similar to what is observed in the crystal structures of the thermophilic aptamer domain.

\section{DISCUSSION}

SAXS provides measurements of the shape and size of molecules in solution. SAXS studies of group I intron and RNase P RNAs indicate that these molecules undergo global collapse, reflected in reduction of $R_{\mathrm{g}}$, upon the addition of low divalent (or high monovalent) cation concentrations (Fang et al. 2000; Russell et al. 2000; Baird et al. 2005; Chauhan et al. 2005). Previous studies have demonstrated the ability of divalent cations to induce native (folded) RNA conformations (Misra and Draper 1998; Koculi et al. 2007). In fact, titrating $\mathrm{Mg}^{2+}$ is a common biophysical approach to tune the stability of RNAs (Pan et al. 1999; Fang et al. 2000; Baird et al. 2005). Therefore, in the present study, we employed a range of $\mathrm{Mg}^{2+}$ concentrations to probe the differential stability of riboswitch aptamer domains. The correlation between overall compaction and native-like conformations has also been established (Fang et al. 2000; Russell et al. 2000; Perez-Salas et al. 2004). These precedents justify employing global compaction as measured by SAXS to report on the metaboliteand $\mathrm{Mg}^{2+}$-induced conformational changes of riboswitch aptamer domains. For the aptamer domains we studied, it was also possible to benchmark the global SAXS parameters of the bound conformations in solution with their respective crystal structures.

Interpretation of our SAXS results is contingent on two assumptions. The first is that the concentration of free $\mathrm{Mg}^{2+}$ in solution is sufficient to stabilize a binding-competent conformation of the RNAs. To address this, we performed SAXS experiments at multiple $\mathrm{Mg}^{2+}$ concentrations and demonstrated metabolite binding even at low $\mathrm{Mg}^{2+}$ concentrations (see thi-box and SAM-I results above, and isothermal titration calorimetry [ITC] experiments below). The second assumption is that the small-molecule metabolites are present at sufficiently high concentration (relative to their dissociation constants) to result in full occupancy of their binding sites in their respective cognate riboswitches. Satisfying this assumption ensures that any observed lack of compaction is not the result of insufficient ligand occupancy. To this end, we determined the dissociation constants for the SAM-I, FMN, and lysine riboswitches using isothermal titration calorimetry (Table 5). The dissociation constant previously determined for the TPP riboswitch (Kulshina et al. 2010) is also included in Table 5. Except for the lysine riboswitch, the ITC experiments were performed under low $\mathrm{Mg}^{2+}$ concentrations to demonstrate that a binding-competent conformation is present under all $\mathrm{Mg}^{2+}$ conditions investigated, thus addressing the validity of the first assumption. The dissociation constants reported in Table 5 demonstrate that our metabolite-bound state SAXS experiments on the TPP, SAM-I, and FMN riboswitches were all carried out under saturating metabolite concentrations. The metabolite was also in sufficient excess for the lysine riboswitch experiments carried out in $10 \mathrm{mM} \mathrm{Mg}^{2+}$. However, for the lysine riboswitch at $1 \mathrm{mM} \mathrm{Mg}^{2+}$ we were only able to obtain a lower bound for the dissociation constant (i.e., $K_{\mathrm{d}}$ is weaker than $20 \mu \mathrm{M})$. This is not surprising considering that

TABLE 3. Global SAXS parameters for the FMN aptamer domain

\begin{tabular}{|c|c|c|c|c|}
\hline \multirow{2}{*}{$\begin{array}{l}{\left[\mathrm{Mg}^{2+}\right]} \\
(\mathrm{mM})\end{array}$} & \multicolumn{2}{|c|}{$R_{\mathrm{g}}( \pm 1 \AA)$} & \multicolumn{2}{|c|}{$D_{\max }( \pm 5 \AA)$} \\
\hline & Free & Bound & Free & Bound \\
\hline 1.5 & 29.4 & 27.9 & 93 & 90 \\
\hline 10 & 29.1 & 28.6 & 91 & 92 \\
\hline
\end{tabular}

The $R_{\mathrm{g}}$ calculated from a crystal structure (PDB ID $3 \mathrm{~F} 2 \mathrm{Q}$ ) is $27.6 \AA$. 


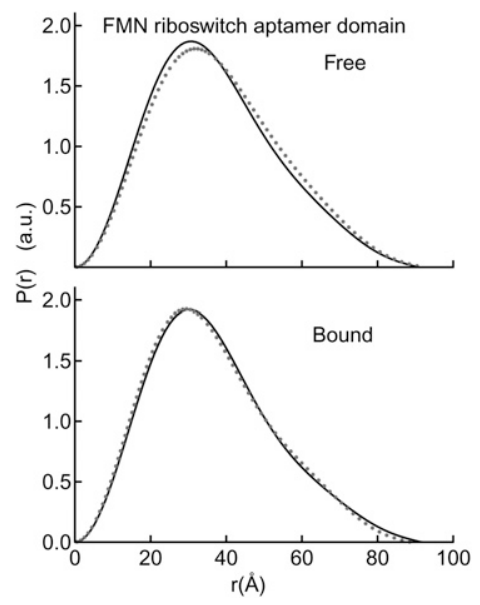

FIGURE 5. Global compaction of the FMN aptamer domain requires minimal $\mathrm{Mg}^{2+}$ and no metabolite. $P(r)$ plots demonstrate the similarity of global conformation for the FMN aptamer domain in all conditions tested; free and bound in $1.5 \mathrm{mM}$ (gray dots) and $10 \mathrm{mM} \mathrm{Mg}^{2+}$ (black lines).

the $R_{\mathrm{g}}$ observed for the lysine riboswitch under this low $\mathrm{Mg}^{2+}$ concentration is considerably larger than that observed at highly stabilizing $\mathrm{Mg}^{2+}$ concentrations (Table 4). Apparently, the C. acetobutylicum lysine riboswitch aptamer domain cannot efficiently bind lysine in physiologic $\mathrm{Mg}^{2+}$ concentrations under our experimental conditions.

A previous fluorescence spectroscopic study of a TPP riboswitch aptamer domain suggested the existence of a stepwise global rearrangement upon metabolite binding from changes observed in local probes distributed throughout the aptamer domain (Lang et al. 2007). Our SAXS studies on this RNA domain now provide direct insight into the nature of the global conformational changes that accompany these local events. By performing SAXS on a thi-box construct engineered to have a predictable change in dimension of one of its three arms (P3ext) (Fig. 3D), we present a first glimpse of the global conformation of the free state of this riboswitch (Fig. 3B,C). Notably, over a range of $\mathrm{Mg}^{2+}$ concentrations $\left(1.5-10 \mathrm{mM} \mathrm{Mg}^{2+}\right)$, the degree of compaction observed upon ligand binding is variable for this TPP aptamer domain. At $1.5 \mathrm{mM} \mathrm{Mg}^{2+}$, the bound conformation is not fully compacted relative to the bound conformations at $2.5 \mathrm{mM}$ or $10 \mathrm{mM} \mathrm{Mg}^{2+}$ (Table 1). Nevertheless, under all $\mathrm{Mg}^{2+}$ conditions probed, this TPP aptamer domain undergoes a metabolite-induced conformational change.

Previous site-directed mutagenesis reports of the SAM-I aptamer domain indicated that this RNA undergoes a large-scale conformational switch upon ligand binding that is dependent on a pseudoknot and kink-turn (McDaniel et al. 2005; Heppell and Lafontaine 2008). This SAMinduced global structural switch is confirmed by our SAXS studies, but only under physiologic $\mathrm{Mg}^{2+}$ conditions. In both $1.5 \mathrm{mM}$ and $2.5 \mathrm{mM} \mathrm{Mg}{ }^{2+}$, the SAM-I riboswitch aptamer domain compacts to dimensions in agreement with the crystal structure upon ligand binding. Unexpectedly, a slight lowering of the $\mathrm{Mg}^{2+}$ concentration to $1 \mathrm{mM}$ results in a more expanded metabolite-bound conformation with an $R_{\mathrm{g}} \sim 30 \AA$ compared with $\sim 26.3 \AA$ in 1.5 $2.5 \mathrm{mM} \mathrm{Mg}^{2+}$. Under this lowered $\mathrm{Mg}^{2+}$ condition, the free conformation is also more expanded than at $1.5-2.5 \mathrm{mM}$ $\mathrm{Mg}^{2+}$ (data not shown). In the presence of $10 \mathrm{mM} \mathrm{Mg}{ }^{2+}$, the metabolite-free SAM-I riboswitch aptamer domain undergoes significant compaction to a near-native conformation with an $R_{\mathrm{g}}$ of $27.5 \AA$ (Table 2). That this conformation requires specific native-like interactions, particularly in the pseudoknot between P2b and P4 (Fig. 1), is evidenced by a lack of compaction observed for a pseudoknot-deficient construct. In this construct, one of the two segments forming the pseudoknot was mutagenized, thereby abrogating the tertiary contact. When examined by SAXS in $10 \mathrm{mM}$ $\mathrm{Mg}^{2+}$, this construct exhibits an $R_{\mathrm{g}}$ of $\sim 35 \AA$ (data not shown). Under this $\mathrm{Mg}^{2+}$ condition, the global SAMinduced switch of the wild-type aptamer domain is nearly eliminated (Table 2), and SAM binding is likely to involve only local structural rearrangements. This demonstrates that, like the TPP aptamer domain, the metabolite-induced structural response of this SAM-I construct is dependent on the overall stability of the RNA under the solution conditions tested.

In stark contrast to the thi-box and SAM-I aptamer domains, the global conformations of the L-box and FMN aptamer domains are unaffected by ligand binding. Thus, there appears to be a spectrum of global responses; some aptamer domains respond to metabolite (thi-box, SAM-I), another only responds to highly stabilizing $\mathrm{Mg}^{2+}$ (L-box), and finally, one aptamer domain appears insensitive to both (FMN) (Fig. 7A,B). The glycine aptamer domain from $V$. cholerae has previously been studied by SAXS (Lipfert et al. 2007), and it, too, exhibits a distinct pattern of response to $\mathrm{Mg}^{2+}$ and metabolite as compared to the four constructs investigated herein (Fig. 7C). We recently observed a large decrease in $R_{\mathrm{g}}$ for the cyclic diguanylate (or GEMM) riboswitch aptamer domain from $V$. cholerae upon binding metabolite in $2.5 \mathrm{mM} \mathrm{Mg}{ }^{2+}$ (Fig. 7C;

TABLE 4. Global SAXS parameters for the lysine aptamer domain

\begin{tabular}{|c|c|c|c|c|}
\hline \multirow{2}{*}{$\begin{array}{l}{\left[\mathrm{Mg}^{2+}\right]} \\
(\mathrm{mM})\end{array}$} & \multicolumn{2}{|c|}{$R_{\mathrm{g}}( \pm 1 \AA)$} & \multicolumn{2}{|c|}{$D_{\max }( \pm 5 \AA)$} \\
\hline & Free & +1 mM lysine & Free & $+1 \mathrm{mM}$ lysine \\
\hline 0.5 & 46.8 & ND & 160 & ND \\
\hline 1.0 & 43.0 & 43.3 & 142 & 145 \\
\hline 2.5 & 44.4 & 43.0 & 142 & 146 \\
\hline 5 & 39.0 & ND & 125 & ND \\
\hline 10 & 39.1 & 39.2 & 125 & 125 \\
\hline
\end{tabular}

The $R_{\mathrm{g}}$ calculated from a crystal structure (PDB ID 3D0U) is $33.9 \AA$; ND indicates the measurement was not determined. 


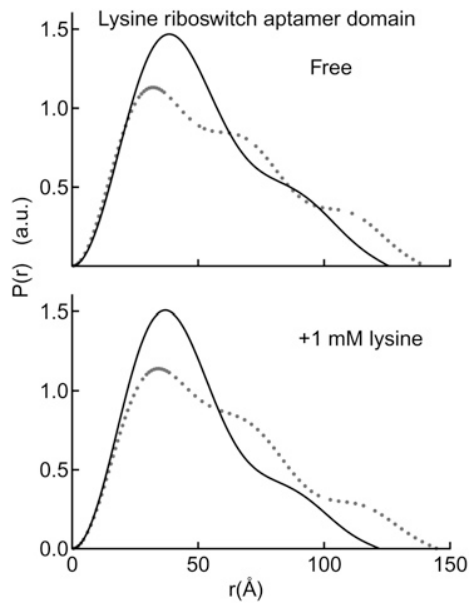

FIGURE 6. $\mathrm{Mg}^{2+}$-dependent response of the lysine riboswitch aptamer domain. A $P(r)$ plot clearly indicates compaction upon addition of highly stabilizing $\mathrm{Mg}^{2+}$ concentrations $(10 \mathrm{mM}$; black lines) as compared to physiologic $\mathrm{Mg}^{2+}$ concentrations $\left(1 \mathrm{mM} \mathrm{Mg}^{2+}\right.$; gray dots). At $10 \mathrm{mM} \mathrm{Mg}{ }^{2+}$, the global conformational change is induced only by $\mathrm{Mg}^{2+}$ (relative to the $1 \mathrm{mM} \mathrm{Mg}^{2+}$ condition) with virtually no difference between the free and bound states. At the low $\mathrm{Mg}^{2+}$ condition, the ligand is sub-saturating (see the text for details).

Kulshina et al. 2009). A similar degree of compaction resulted in the absence of cylic diguanlyate when highly stabilizing $\mathrm{Mg}^{2+}$ concentrations $(10 \mathrm{mM})$ were present, akin to the behavior observed herein for the SAM-I riboswitch aptamer domain. Certainly, the degree of global collapse observed in the study of any of these riboswitch aptamer domains does not exclude the possibility that local conformational changes resulting from metabolite binding may be an important aspect of riboswitch function. Finally, it is important to note that our SAXS study, along with the glycine and cyclic diguanylate aptamer domain studies, was performed with constructs having the aptamer domain divorced from the expression platform. In order to more fully understand the structural basis of riboswitch function, future studies would require the inclusion of both the aptamer domain and expression platforms.
The stabilizing conditions required to achieve the most compact global conformation differ among the aptamer domains investigated (Fig. 7B). For example, the thi-box, SAM-I, and FMN aptamer domains are all able to achieve maximally compacted, ligand-bound conformations under minimal (physiologic) $\mathrm{Mg}^{2+}$ concentrations $(\leq 2.5 \mathrm{mM}$ ). The FMN aptamer domain is also fully compacted in the absence of metabolite under this $\mathrm{Mg}^{2+}$ condition. Somewhat akin to this behavior, the lysine aptamer domain from T. maritima is completely compact when crystallized in the absence of $\mathrm{Mg}^{2+}$ (Serganov et al. 2008). In contrast, the C. acetobutylicum L-box studied herein, along with that from B. subtilis (Garst et al. 2008), does not mimic the dimensions of the reported crystal structures under physiologic $\mathrm{Mg}^{2+}$ conditions either in the absence or presence of lysine. It is not until more highly stabilizing $\mathrm{Mg}^{2+}$ concentrations are added $(\sim 5 \mathrm{mM})$ that these L-box aptamer domains compact to dimensions in agreement with the crystal structure (Fig. 6; Garst et al. 2008). Thus, the variable stability of riboswitch aptamer domains is evident both across riboswitch classes and within a single class (L-box).

Biochemical and genetic differences have also been observed within individual classes of riboswitches. Previously, Mulhbacher and Lafontaine (2007) studied four guanine riboswitches found in the $B$. subtilis genome. In a separate study, Henkin and coworkers investigated 11 SAM-I riboswitches present in the same organism (Tomsic et al. 2007). Within each class (SAM-I and guanine), the multiple constructs exhibit sequence differences in nonconserved regions. Mulhbacher and Lafontaine (2007) performed in vitro 2-aminopurine binding assays and observed that the different guanine riboswitch aptamer domains exhibit a range of dissociation constants between $0.59 \mu \mathrm{M}$ and $9.79 \mu \mathrm{M}$. Similarly, Henkin and coworkers (Tomsic et al. 2007) employed ultrafiltration binding assays and determined a wide range of dissociation constants, between $14 \mathrm{nM}$ and $3.5 \mu \mathrm{M}$, for each of the SAM-I aptamer domains. In both studies, the differing dissociation constants were found generally to correlate with transcription

TABLE 5. Thermodynamic parameters determined by ITC

\begin{tabular}{|c|c|c|c|c|c|}
\hline $\begin{array}{l}\text { Riboswitch } \\
\text { aptamer domain }\end{array}$ & $\begin{array}{c}\Delta \mathrm{H} \\
(\mathrm{kcal} / \mathrm{mol})\end{array}$ & $\begin{array}{c}-T \Delta S \\
(\mathrm{kcal} / \mathrm{mol})\end{array}$ & $\begin{array}{c}K_{\mathrm{d}} \\
(\mu \mathrm{M})\end{array}$ & $n$ & $\begin{array}{c}\text { [Metabolite] } \\
\text { (for SAXS) }\end{array}$ \\
\hline TPP & $-24.0 \pm 1.4$ & $14.7 \pm 1.4$ & $0.1975 \pm 0.007$ & $0.88 \pm 0.1$ & $100 \mu \mathrm{M}$ \\
\hline SAM-I & $-20.1 \pm 0.4$ & $11.8 \pm 0.4$ & $1.35 \pm 0.15$ & $0.82 \pm 0.04$ & $1 \mathrm{mM}$ \\
\hline FMN & $-14.5 \pm 0.4$ & 5.7 & $0.613 \pm 0.110$ & $0.93 \pm 0.02$ & $100 \mu \mathrm{M}$ \\
\hline Lysine & ND & ND & $\geq 20$ & ND & $1 \mathrm{mM}$ \\
\hline Lysine $\left(10 \mathrm{mM} \mathrm{Mg}^{2+}\right)^{\mathrm{b}}$ & $-23.3 \pm 0.6$ & $15.2 \pm 0.8$ & $1.8 \pm 0.4$ & $0.89 \pm 0.15$ & $1 \mathrm{mM}$ \\
\hline
\end{tabular}

Errors are reported as the square root of the variance for SAM-I and lysine aptamer domains and as the error in the fit to the data for the FMN aptamer domain; ND indicates the measurement was not determined.

${ }^{a}$ Parameters for the TPP riboswitch aptamer domain in $0.5 \mathrm{mM} \mathrm{Mg}^{2+}$ are from Kulshina et al. (2010).

bITC experiments for SAM-I, FMN, and lysine riboswitch aptamer domains were performed at $1 \mathrm{mM} \mathrm{Mg}^{2+}$. The lysine riboswitch aptamer domain was also examined at $10 \mathrm{mM} \mathrm{Mg}^{2+}$ due to experimental limitations (see Materials and Methods) resulting in insufficient binding observed at $1 \mathrm{mM} \mathrm{Mg}^{2+}$. 
A

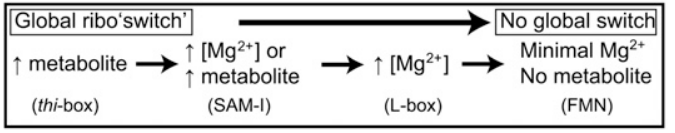
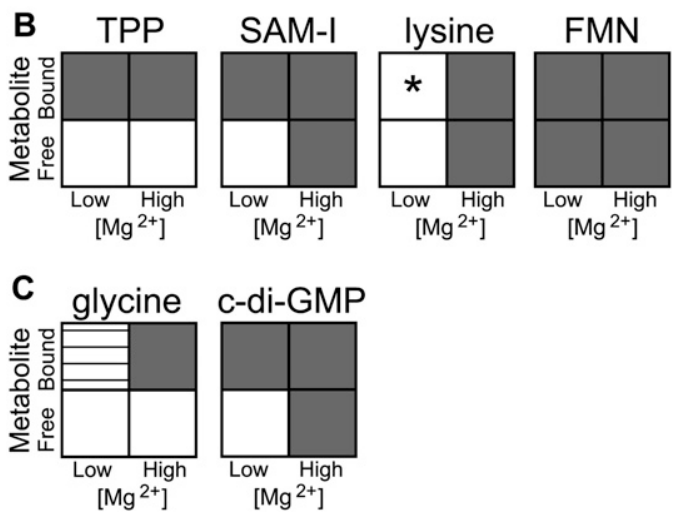

FIGURE 7. Alternative simplified schematics of global conformational responses induced by $\mathrm{Mg}^{2+}$ and metabolite. Each riboswitch investigated in this study exhibits idiosyncratic responses to the conditions probed. (A) Conditions are described that yield a globally compacted conformation for each aptamer domain as measured by $R_{\mathrm{g}}$. (B) A matrix describing the degree of compaction relative to the low $\left[\mathrm{Mg}^{2+}\right]$, no metabolite condition is diagrammed as follows: (white) expanded; (gray) fully compacted; (horizontal lines) partially compacted. ${ }^{*}$ ) As indicated in the Discussion, lysine is present at sub-saturating concentration in our low- $\mathrm{Mg}^{2+}$ concentration condition. (C) The same matrix is presented for the glycine and cyclic diguanylate aptamer domain conformations, data adapted from Lipfert et al. (2007) and Kulshina et al. (2009), respectively. The low $\left[\mathrm{Mg}^{2+}\right]$ reference point is chosen as $2.5 \mathrm{mM} \mathrm{Mg}^{2+}$ for TPP, SAM-I, lysine, and cyclic diguanylate aptamer domains; and $1.5 \mathrm{mM} \mathrm{Mg}^{2+}$ for the FMN and glycine aptamer domains. The high $\left[\mathrm{Mg}^{2+}\right]$ reference point is $10 \mathrm{mM} \mathrm{Mg}^{2+}$ in all cases. Global changes are reported for conformations that exhibit differences in $R_{\mathrm{g}}>1.5 \AA$.

termination efficiencies in vivo as measured by RT-qPCR. Together, these studies suggest that genetic regulation by riboswitches may be tuned by sequence variability.

Our SAXS study reveals variation in aptamer domain structural responses across riboswitch classes. Hence, both sampling across classes and sampling within individual classes (above) suggest that each riboswitch construct may have inherent sequence features that result in its unique genetic, biochemical, and structural responses to metabolite. Taken together, these biochemical, genetic, and structural differences may actually demonstrate that riboswitches have been tuned to their specific genetic context, perhaps to local constraints required for efficient gene regulation (Mulhbacher and Lafontaine 2007; Tomsic et al. 2007). For example, the B. subtilis ribD FMN riboswitch is involved in transcriptional regulation. During the process of transcription by RNA polymerase, thermodynamic equilibrium is not achieved between the riboswitch and its metabolite (Wickiser et al. 2005b). This riboswitch is under kinetic control, and a binding competent conformation must be rapidly formed during transcription. Our
SAXS data indicate that this riboswitch aptamer domain is globally compact even in the absence of metabolite. This pre-compacted conformation may allow for rapid recognition of the metabolite and, in turn, rapid transduction of the regulatory signal within an appropriate timeframe. Other questions regarding riboswitch function will require that the folding and switching properties of the RNA be probed while being transcribed by its cognate polymerase.

\section{MATERIALS AND METHODS}

\section{Sample preparation}

RNA samples were prepared using standard in vitro run-off transcription procedures either from linearized plasmids (Rupert and Ferré-D'Amaré 2004) or PCR templates (Xiao et al. 2008). The TPP and FMN and lysine aptamer domain constructs were transcribed from linearized plasmids containing the RNA sequence of interest along with a self-cleaving Hammerhead ribozyme at the $5^{\prime}$ end and VS ribozyme substrate helix at the $3^{\prime}$ end (Ferré-D’Amaré and Doudna 1996). A plasmid containing the trans-acting VS ribozyme was added to the transcription reaction to achieve a homogeneous $3^{\prime}$ end. The SAM-I construct was amplified by large-scale PCR. Following PCR, the whole 3-mL reaction was added to a $10-\mathrm{mL}$ total volume transcription reaction. RNAs were purified using denaturing PAGE. Bands of appropriate length were cut from the gel and crushed followed by overnight agitation and elution into water at $4^{\circ} \mathrm{C}$. The RNAs were concentrated and desalted using Centricon 70 (Millipore) filters and stored in water at $4^{\circ} \mathrm{C}$ until experimentation.

\section{SAXS experiments}

All SAXS experiments were performed at the BioCAT beamline at the Advanced Photon Source (APS) at Argonne National Laboratories. Most samples were prepared on-site prior to experimentation. Some samples were prepared prior to shipping on dry ice to BioCAT. Good agreement was observed between samples prepared on-site or pre-prepared and shipped. Generally, concentrated stock RNA samples, except the lysine riboswitch aptamer domain, were diluted to a final concentration between 0.3 and $0.5 \mathrm{mg} / \mathrm{mL}$ in $20 \mathrm{mM}$ Tris- $\mathrm{HCl}(\mathrm{pH} 8)$ and $40 \mathrm{mM} \mathrm{NaCl}$ with a final volume of $100 \mu \mathrm{L}$. The lysine riboswitch aptamer domain was equilibrated in a buffer comprised of $60 \mathrm{mM}$ Tris$\mathrm{HCl}$ ( $\mathrm{pH} 8$ ), $30 \mathrm{mM} \mathrm{NaCl}$, and $50 \mathrm{mM} \mathrm{KCl}$. Samples were heated for $2 \mathrm{~min}$ to $85^{\circ} \mathrm{C}$ followed by cooling for $10 \mathrm{~min}$ at room temperature. $\mathrm{MgCl}_{2}$ was then added to achieve the desired final total concentration. The concentration of free $\mathrm{Mg}^{2+}$ in solution (i.e., its activity) may be slightly lower due to the relatively high concentration of RNA present in the SAXS experiments; the free $\mathrm{Mg}^{2+}$ is likely within $\sim 0.25-0.5 \mathrm{mM}$ of the total $\mathrm{Mg}^{2+}$ under these experimental conditions (Baird et al. 2005). Prior to SAXS measurements, the samples were equilibrated for $\geq 5 \mathrm{~min}$ at $37^{\circ} \mathrm{C}$. Buffer solutions were prepared at the same time as sample solutions, replacing RNA with water. In some cases, sample buffers were exchanged three times using an Amicon microconcentrator filter (Millipore) spun at $12,000 \mathrm{~g}$ for $30 \mathrm{~min}$ to ensure identical buffer/sample conditions. There were no noticeable differences in 
the quality of the data obtained from buffers generated by diluting stock solutions or by the microfiltration process. Data collection was performed in a temperature-equilibrated brass tower at $37^{\circ} \mathrm{C}$. Solutions were under continuous flow in a $1.5-\mathrm{mm}$ capillary during exposure to the X-ray beam. Fifteen 1-sec exposures were separately collected for the buffer and sample. Following data collection of the metabolite-free condition, $\sim 1 \mu \mathrm{L}$ of appropriate metabolite was added to saturating concentration as follows: TPP, $100 \mu \mathrm{M}$ final; SAM, 1-2 mM final; lysine, $1 \mathrm{mM}$ final; FMN, $100 \mu \mathrm{M}$ final.

To demonstrate that the aptamer domains are monomeric, we performed several analyses. First, CRYSOL (Svergun et al. 1995) was used to calculate the expected radius of gyration for each crystal structure (TPP, 2HOJ; SAM-I, 2GIS; FMN, 3F2Q; lysine, 3D0U), having removed bound solvent and metal ions. CRYSOL assumes the presence of a solvation layer surrounding the crystal structure to mimic the molecule in solution (Svergun et al. 1995). The SAXS-derived $R_{\mathrm{g}}$ of the fully compacted conformation of each aptamer domain bound to its metabolite was in agreement with these calculations, with the TPP aptamer domain exhibiting slightly more compaction than estimated from the calculation, which may be due to the assumption of a uniform solvent layer. Additionally, cytochrome $c$ scattering was used as a molecular weight standard. Comparison of the forward scattering, $I(0)$, for cytochrome $c$ and the RNA constructs yields an estimate of molecular weight for the RNAs studied (Lipfert et al. 2007). In cases where scattering profiles for multiple aptamer domains were collected on the same day, the molecular weight calculation could be performed by comparing the $I(0)$ s for two distinct RNAs. Molecular weights calculated from forward scattering were in agreement with those estimated based on RNA mass ( $\sim 330 \mathrm{~g} / \mathrm{mol} / \mathrm{nt})$. The above combined analyses indicate that the aptamers are monomeric under all metabolite-bound conditions examined. In the metabolite-free condition, $I(0)$ remained constant for each construct, indicating that in the absence of metabolite the molecule is still monomeric.

\section{SAXS data analysis}

Scattering data were reduced to a one-dimensional scattering plot using IGOR PRO (WaveMetrics) software. Data were separately averaged for each solution followed by subtraction of the buffer scattering from the sample. The $q$-range used for data analysis was generally between 0.01 and $0.2 \AA^{-1}$. The reported $R_{\mathrm{g}}$ values were calculated from a Guinier plot in the $q$-range such that $q_{\max } \times R_{\mathrm{g}}$ $\sim 1.0$ and $\sim 1.3$. $R_{\mathrm{g}}$ values calculated at the different $q_{\max } \times R_{\mathrm{g}}$ ranges were distinct. However, the overall change in $R_{\mathrm{g}}$ from the metabolite-free to metabolite-bound conformation was found to be consistent in both ranges. Values reported are for $q_{\max } \times R_{g} \sim 1$, and the errors are estimated based on some experiments that were repeated with multiple samples. The Moore autocorrelation function was used to generate the probability distribution, $P(r)$. $P(r)$ plots presented herein are normalized to $I(0)$ to account for differences in concentration. $R_{\mathrm{g}}$ values determined from the $P(r)$ calculation were in good agreement with those obtained from Guinier analysis, generally slightly higher but within $\sim 1 \AA$. The GNOM software (Svergun 1992) was also used to calculate $P(r)$ plots in subsequent analysis. The probability distribution curves calculated from GNOM and the Moore autocorrelation were in good agreement in overall shape, $D_{\max }$, and $R_{\mathrm{g}}$.

\section{Ab initio reconstructions of the TPP aptamer domain}

GNOM (Svergun 1992), DAMMIN (Svergun 1999), and DAMAVER (Volkov and Svergun 2003) from the ATSAS suite of programs were used to generate $a b$ initio reconstructions of the TPP aptamer domain under various conditions. Scripts made available by J. Lipfert (Lipfert et al. 2007) were used to automate the process. We used a range of $D_{\max }$ values from 50 to $200 \AA$ in $2-\AA$ increments as input for the GNOM program. Agreement between the scattering data and the GNOM fit to the data was used as a criterion to identify the $D_{\max }$ that best fit the data. These values were in agreement with the $D_{\max }$ determined from the Moore autocorrelation function. Because the $D_{\max }$ is used to determine the initial search volume in DAMMIN, several values were chosen for reconstruction. For each $D_{\max }$ chosen, nine independent reconstructions were performed. The DAMAVER software was used to align and average the reconstructions separately for each condition. DAMAVER produces a filtered dummy atom model. Using Situs (Wriggers et al. 1999) with voxel spacing of $2 \AA$, we converted the dummy atom model into an electron density map of the solution-derived model. The reconstructed shapes initiated from the various initial search volumes were in general shape agreement. The normalized spatial discrepancy (NSD) is used to describe the level of agreement between the individual models generated for each condition (Kozin and Svergun 2001). An NSD of zero indicates that two models are identical while an NSD $>1$ is indicative of models that are not in agreement. The NSD for the nine TPP-bound models is 0.62 . The wildtype TPP-free reconstructions have an overall NSD value of 0.84 . This suggests that while the nine TPP-free reconstructions of the wild-type molecule are self-similar $(\mathrm{NSD}<1)$, they may exhibit higher flexibility in their conformations than the bound conformation. The extended molecule in the TPP-free conformation exhibits a similar NSD (0.82) to the wild-type TPP-free conformation, again suggesting that the TPP-free conformation is more flexible than the bound conformation. The agreement between the crystal structure (PDB ID: 2HOJ) and the SAXS-derived electron density is demonstrated through the calculation of a crosscorrelation coefficient (0.89) using Situs.

Reconstruction figures were generated using the UCSF Chimera software (Pettersen et al. 2004).

\section{ITC experiments}

For ITC experiments, RNA was prepared under the same conditions used for SAXS experiments with the following exceptions: HEPES-KOH ( $\mathrm{pH} 7.5$ ) was used in place of Tris- $\mathrm{HCl}(\mathrm{pH} 8)$, and samples were dialyzed overnight at room temperature into $500 \mathrm{~mL}$ of buffer in a D-tube dialyzer (Novagen). Concentrated metabolite stocks were diluted to final concentration in the dialysis buffer. Final RNA and metabolite concentrations used in the experiments are as follows: [SAM-I aptamer domain] $=20 \mu \mathrm{M}(0.64 \mathrm{mg} / \mathrm{mL})$; $[\mathrm{SAM}]=200 \mu \mathrm{M}$; $[\mathrm{FMN}$ aptamer domain $]=16 \mu \mathrm{M}(0.77 \mathrm{mg} / \mathrm{mL})$; $[\mathrm{FMN}]=300 \mu \mathrm{M}$; [lysine aptamer domain] $=25 \mu \mathrm{M}(1.54$ $\mathrm{mg} / \mathrm{mL}$ ); [lysine] $=980 \mu \mathrm{M}$. Results are reported for experiments performed in duplicate with the exception that the FMN riboswitch aptamer domain data are reported for only one experiment. The lysine riboswitch aptamer domain ITC experiments were performed in $1 \mathrm{mM}$ and $10 \mathrm{mM} \mathrm{Mg}^{2+}$. ITC experiments for the SAM-I and FMN riboswitch aptamer domains were performed 
in $1 \mathrm{mM} \mathrm{Mg}{ }^{2+}$ to probe the lower range of $\mathrm{Mg}^{2+}$ concentrations used in the SAXS experiments. This ensures that under all $\mathrm{Mg}^{2+}$ conditions examined in the SAXS experiments, the ligand was added to a final concentration of saturating metabolite, with the caveat that the lysine riboswitch aptamer domain may not efficiently bind lysine at this $\mathrm{Mg}^{2+}$ concentration. Addition of highly stabilizing $\mathrm{Mg}^{2+}$ concentrations resulted in tighter binding (e.g., lysine riboswitch). All ITC experiments were performed at $37^{\circ} \mathrm{C}$ using an $\mathrm{iTC}_{200}$ microcalorimeter (MicroCal). The binding parameters for the lysine riboswitch aptamer domain could not be adequately determined at $1 \mathrm{mM} \mathrm{Mg}^{2+}$ due to complications of the experimental set-up. To adequately observe the binding isotherm of this weak binding event, a relatively high concentration of RNA is required $(\sim 1 \mathrm{mM})$. At this RNA concentration, the heat of binding (calorimetric signal) is too high to be detected on the iTC200. In all experiments, the interval between successive metabolite injections was adjusted to allow equilibration as judged by the signal returning to the baseline. For all RNA constructs examined, this interval did not exceed $5 \mathrm{~min}$.

\section{ACKNOWLEDGMENTS}

We thank S. Zaheer, L. Guo, and T. Sosnick for assistance with data collection and processing; and M. Lau, J. Zhang, T. Hamma, N. Kulshina, J. Posakony, J. Pitt, A. Roll-Mecak, and S. Woodson for discussions. We thank J. Lipfert for sharing scripts (Lipfert et al. 2007) for automation of the GNOM and DAMMIN software packages. This work was supported by an NIH grant to A.R.F. (GM63576) and by the Howard Hughes Medical Institute. A.R.F.-D. is an Investigator of the Howard Hughes Medical Institute. Use of the APS was supported by the U.S. Department of Energy, Basic Energy Sciences, Office of Science, under Contract No. W-31-109ENG-38. BioCAT is a National Institutes of Health-supported Research Center RR-08630. The content is solely the responsibility of the authors and does not necessarily reflect the official views of the National Center for Research Resources or the National Institutes of Health.

Received July 30, 2009; accepted December 3, 2009.

\section{REFERENCES}

Baird NJ, Westhof E, Qin H, Pan T, Sosnick TR. 2005. Structure of a folding intermediate reveals the interplay between core and peripheral elements in RNA folding. J Mol Biol 352: 712-722.

Batey RT, Gilbert SD, Montange RK. 2004. Structure of a natural guanine-responsive riboswitch complexed with the metabolite hypoxanthine. Nature 432: 411-415.

Chauhan S, Caliskan G, Briber RM, Perez-Salas U, Rangan P, Thirumalai D, Woodson SA. 2005. RNA tertiary interactions mediate native collapse of a bacterial group I ribozyme. $J \mathrm{Mol}$ Biol 353: 1199-1209.

Dann CE III, Wakeman CA, Sieling CL, Baker SC, Irnov I, Winkler WC. 2007. Structure and mechanism of a metal-sensing regulatory RNA. Cell 130: 878-892.

Edwards TE, Ferré-D'Amaré AR. 2006. Crystal structures of the thibox riboswitch bound to thiamine pyrophosphate analogs reveal adaptive RNA-small molecule recognition. Structure 14: 14591468.

Edwards TE, Klein DJ, Ferré-D’Amaré AR. 2007. Riboswitches: Smallmolecule recognition by gene regulatory RNAs. Curr Opin Struct Biol 17: 273-279.
Ellington AD, Szostak JW. 1990. In vitro selection of RNA molecules that bind specific ligands. Nature 346: 818-822.

Fang X, Littrell K, Yang XJ, Henderson SJ, Siefert S, Thiyagarajan P, Pan T, Sosnick TR. 2000. $\mathrm{Mg}^{2+}$-dependent compaction and folding of yeast tRNA ${ }^{\text {Phe }}$ and the catalytic domain of the B. subtilis RNase P RNA determined by small-angle X-ray scattering. Biochemistry 39: 11107-11113.

Ferré-D'Amaré AR, Doudna JA. 1996. Use of cis- and trans-ribozymes to remove $5^{\prime}$ and $3^{\prime}$ heterogeneities from milligrams of in vitro transcribed RNA. Nucleic Acids Res 24: 977-978.

Garst AD, Héroux A, Rambo RP, Batey RT. 2008. Crystal structure of the lysine riboswitch regulatory mRNA element. J Biol Chem 283: 22347-22351.

Gilbert SD, Love CE, Edwards AL, Batey RT. 2007. Mutational analysis of the purine riboswitch aptamer domain. Biochemistry 46: $13297-13309$.

Henkin TM. 2008. Riboswitch RNAs: Using RNA to sense cellular metabolism. Genes \& Dev 22: 3383-3390.

Heppell B, Lafontaine DA. 2008. Folding of the SAM aptamer is determined by the formation of a K-turn-dependent pseudoknot. Biochemistry 47: 1490-1499.

Koculi E, Hyeon C, Thirumalai D, Woodson SA. 2007. Charge density of divalent metal cations determines RNA stability. J Am Chem Soc 129: 2676-2682.

Kozin MB, Svergun DI. 2001. Automated matching of high- and lowresolution structural models. J Appl Crystallogr 34: 33-41.

Kulshina N, Baird NJ, Ferré-D'Amaré AR. 2009. Recognition of the bacterial second messenger cyclic diguanylate by its cognate riboswitch. Nat Struct Mol Biol 16: 1212-1217.

Kulshina N, Edwards TE, Ferré-D’Amaré AR. 2010. Thermodynamic analysis of ligand binding and ligand binding-induced tertiary structure formation by the thiamine pyrophosphate riboswitch. RNA 16: 186-196.

Lang K, Rieder R, Micura R. 2007. Ligand-induced folding of the thiM TPP riboswitch investigated by a structure-based fluorescence spectroscopic approach. Nucleic Acids Res 35: 5370-5378.

Lemay JF, Penedo JC, Tremblay R, Lilley DM, Lafontaine DA. 2006. Folding of the adenine riboswitch. Chem Biol 13: 857-868.

Lipfert J, Das R, Chu VB, Kudaravalli M, Boyd N, Herschlag D, Doniach S. 2007. Structural transitions and thermodynamics of a glycine-dependent riboswitch from Vibrio cholerae. J Mol Biol 365: 1393-1406.

McDaniel BA, Grundy FJ, Henkin TM. 2005. A tertiary structural element in $\mathrm{S}$ box leader RNAs is required for $S$-adenosylmethioninedirected transcription termination. Mol Microbiol 57: 10081021.

Misra VK, Draper DE. 1998. On the role of magnesium ions in RNA stability. Biopolymers 48: 113-135.

Montange RK, Batey RT. 2006. Structure of the $S$-adenosylmethionine riboswitch regulatory mRNA element. Nature 441: 1172-1175.

Montange RK, Batey RT. 2008. Riboswitches: Emerging themes in RNA structure and function. Annu Rev Biophys 37: 117-133.

Mulhbacher J, Lafontaine DA. 2007. Ligand recognition determinants of guanine riboswitches. Nucleic Acids Res 35: 5568-5580.

Nakamura TM, Wang YH, Zaug AJ, Griffith JD, Cech TR. 1995. Relative orientation of RNA helices in a group I ribozyme determined by helix extension electron microscopy. EMBO $J$ 14: 4849-4859.

Noeske J, Buck J, Furtig B, Nasiri H, Schwalbe H, Wohnert J. 2006. Interplay of 'induced fit' and preorganization in the ligand induced folding of the aptamer domain of the guanine binding riboswitch. Nucleic Acids Res 35: 572-583.

Noeske J, Schwalbe H, Wohnert J. 2007. Metal-ion binding and metalion induced folding of the adenine-sensing riboswitch aptamer domain. Nucleic Acids Res 35: 5262-5273.

Ottink O, Rampersad S, Tessari M, Zaman G, Heus H, Wijmenga S. 2007. Ligand-induced folding of the guanine-sensing riboswitch is controlled by a combined predetermined induced fit mechanism. RNA 13: 2202-2212. 
Pan J, Thirumalai D, Woodson SA. 1999. Magnesium-dependent folding of self-splicing RNA: Exploring the link between cooperativity, thermodynamics, and kinetics. Proc Natl Acad Sci 96: 6149-6154.

Perez-Salas UA, Rangan P, Krueger S, Briber RM, Thirumalai D, Woodson SA. 2004. Compaction of a bacterial group I ribozyme coincides with the assembly of core helices. Biochemistry 43: 17461753.

Pettersen EF, Goddard TD, Huang CC, Couch GS, Greenblatt DM, Meng EC, Ferrin TE. 2004. UCSF Chimera-a visualization system for exploratory research and analysis. J Comput Chem 25: 16051612.

Rieder R, Lang K, Graber D, Micura R. 2007. Ligand-induced folding of the adenosine deaminase A-riboswitch and implications on riboswitch translational control. ChemBioChem 8: 896-902.

Rupert PB, Ferré-D’Amaré AR. 2004. Crystallization of the hairpin ribozyme: Illustrative protocols. Methods Mol Biol 252: 303-311.

Russell R, Millett IS, Doniach S, Herschlag D. 2000. Small angle X-ray scattering reveals a compact intermediate in RNA folding. Nat Struct Biol 7: 367-370.

Serganov A, Polonskaia A, Phan AT, Breaker RR, Patel DJ. 2006. Structural basis for gene regulation by a thiamine pyrophosphatesensing riboswitch. Nature 441: 1167-1171.

Serganov A, Huang L, Patel D. 2008. Structural insights into amino acid binding and gene control by a lysine riboswitch. Nature 455: 1263-1267.

Serganov A, Huang L, Patel D. 2009. Coenzyme recognition and gene regulation by a flavin mononucleotide riboswitch. Nature 458: 233-237.

Stoddard C, Gilbert S, Batey R. 2008. Ligand-dependent folding of the three-way junction in the purine riboswitch. RNA 14: 675-684.

Svergun DI. 1992. Determination of the regularization parameter in indirect-transform methods using perceptual criteria. J Appl Crystallogr 25: 495-503.
Svergun DI. 1999. Restoring low resolution structure of biological macromolecules from solution scattering using simulated annealing. Biophys J 76: 2879-2886.

Svergun DI, Barberato C, Koch MHJ. 1995. CRYSOL-a program to evaluate $\mathrm{x}$-ray solution scattering of biological macromolecules from atomic coordinates. J Appl Crystallogr 28: 768-773.

Thore S, Leibundgut M, Ban N. 2006. Structure of the eukaryotic thiamine pyrophosphate riboswitch with its regulatory ligand. Science 312: 1208-1211.

Thore S, Frick C, Ban N. 2008. Structural basis of thiamine pyrophosphate analogues binding to the eukaryotic riboswitch. J Am Chem Soc 130: 8116-8117.

Tomsic J, Mcdaniel B, Grundy F, Henkin T. 2007. Natural variability in $S$-adenosylmethionine (SAM)-dependent riboswitches: S-box elements in Bacillus subtilis exhibit differential sensitivity to SAM in vivo and in vitro. J Bacteriol 190: 823-833.

Volkov VV, Svergun DI. 2003. Uniqueness of ab initio shape determination in small-angle scattering. J Appl Crystallogr 36: 860-864.

Wickiser JK, Cheah MT, Breaker RR, Crothers DM. 2005a. The kinetics of ligand binding by an adenine-sensing riboswitch. Biochemistry 44: 13404-13414.

Wickiser JK, Winkler WC, Breaker RR, Crothers DM. 2005b. The speed of RNA transcription and metabolite binding kinetics operate an FMN riboswitch. Mol Cell 18: 49-60.

Winkler WC, Breaker RR. 2005. Regulation of bacterial gene expression by riboswitches. Annu Rev Microbiol 59: 487-517.

Winkler W, Nahvi A, Breaker R. 2002. Thiamine derivatives bind messenger RNAs directly to regulate bacterial gene expression. Nature 419: 952-956.

Wriggers W, Milligan RA, McCammon JA. 1999. Situs: A package for docking crystal structures into low-resolution maps from electron microscopy. J Struct Biol 125: 185-195.

Xiao H, Edwards TE, Ferré-D’Amaré AR. 2008. Structural basis for specific, high-affinity tetracycline binding by an in vitro evolved aptamer and artificial riboswitch. Chem Biol 15: 1125-1137. 
RNA 16: 598-609 (2010)

\section{Idiosyncratically tuned switching behavior of riboswitch aptamer domains revealed by comparative small-angle X-ray scattering analysis}

\section{NATHAN J. BAIRD and ADRIAN R. FERRÉ-D'AMARÉ}

In the footnotes to Tables 1-4, the values of radii of gyration calculated from atomic coordinates were incorrect. The correct values are $20.7 \AA$, 21.6 $\AA$, 23.0 $\mathrm{A}$, and $29.1 \AA$ for PDB files $2 \mathrm{HOJ}, 2 \mathrm{GIS}, 3 \mathrm{~F} 2 \mathrm{Q}$, and 3D0U, respectively.

The authors apologize for any confusion these errors may have caused, though they have noted the errors do not affect the results or conclusions of the paper. 

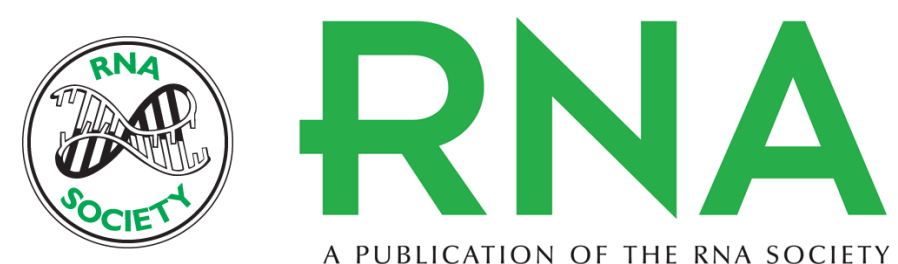

A PUBLICATION OF THE RNA SOCIETY

\title{
Idiosyncratically tuned switching behavior of riboswitch aptamer domains revealed by comparative small-angle X-ray scattering analysis
}

\author{
Nathan J. Baird and Adrian R. Ferré-D'Amaré
}

RNA 2010 16: 598-609 originally published online January 27, 2010

Access the most recent version at doi:10.1261/rna.1852310

\section{Related Content}

References

\author{
Articles cited in: \\ http://rnajournal.cshlp.org/content/16/3/598.full.htmI\#related-urls
}

\section{Erratum}

RNA July , 2010 16: 1447

This article cites 52 articles, 7 of which can be accessed free at: http://rnajournal.cshlp.org/content/16/3/598.full.html\#ref-list-1

\section{License}

Email Alerting Receive free email alerts when new articles cite this article - sign up in the box at the Service top right corner of the article or click here. 